\title{
Non-invasive cardiac output measurement in low and very low birth weight infants: a method comparison
}

\author{
Oswin Grollmuss ${ }^{1}$ * and Patricia Gonzalez ${ }^{2}$ \\ ${ }^{1}$ Centre Chirurgical Marie Lannelongue, INSERM 999, Université Paris XI Sud, Orsay, France \\ 2 Institut de Puériculture et de Périnatalogie, Université Paris V Descartes, Clamart, France
}

Edited by:

Cecile Tissot, The University

Children's Hospital, Switzerland

Reviewed by:

Yves Durandy, Centre Chirurgical

Marie Lannelongue, France

Jeffrey Feinstein, Stanford University,

USA

${ }^{*}$ Correspondence:

Oswin Grollmuss, Centre Chirurgical

Marie Lannelongue, INSERM 999,

Université Paris XI, 133, Avenue de la

Résistance, 92350 Le Plessis

Robinson, Orsay, France

e-mail: osgro@aol.com
Background: Cardiac output (CO) measurement in low (LBW) and very low (VLBW) birth weight infants is difficult. Hitherto, sporadical transthoracic echocardiography (TTE) is the only non-invasive measurement method. Electrical velocimetry (EV) has been evaluated as an alternative in normal weight newborns.

Objectives: The study was designed to evaluate if EV could be interchangeable with TTE even in LBW and VLBW infants.

Methods: In 28 (17 LBW, 11 VLBW) pre-mature newborns, $n=228$ simultaneous TTE (trans-aortic Doppler), and EV measurements (134 LBW, 94 VLBW) of stroke volume (SV) and heart rate $(\mathrm{HR})$ were performed, thereof calculating body weight indexed $\mathrm{SV}\left(=\mathrm{SV}^{*}\right)$ and $\mathrm{CO}(=\mathrm{CO} *)$ for all patients and the subgroups. Method comparison was performed by Bland-Altman plot, method precision expressed by calculation of the coefficient of variation (CV).

Results: Mean CO* in all patients was $256.4 \pm 44.8$ (TTE) and $265.3 \pm 48.8(\mathrm{EV}) \mathrm{ml} / \mathrm{kg} / \mathrm{min}$. Bias and precision were clinically acceptable, limits of agreement within the $30 \%$ criterion for method interchangeability (17). According to their different anatomic dimensions and pathophysiology, there were significant differences of $\mathrm{SV}\left({ }^{*}\right), \mathrm{HR}$, and $\mathrm{CO}^{*}$ for LBW and VLBW infants as well for inotropic treatment and ventilation mode.

Conclusion: Extending recent publications on EV/TTE comparison in newborns, this study suggests that EV is also applicable in LWBNLBW infants as a safe and easy to handle method for continuous $\mathrm{CO}$ monitoring in the NICU and PCICU.

Keywords: low birth weight infants, very low birth weight infants, neonatal intensive care unit, pediatric cardiac intensive care unit, stroke volume, cardiac output, electrical velocimetry, transthoracic echocardiograph

\section{INTRODUCTION}

Information about cardiac output (CO) in newborn and especially in pre-term, low birth weight (LBW), and very low birth weight (VLBW) infants is difficult to obtain. However, this information is particularly important in such patients with their numerous circulatory features [heart-lung interaction $(1,2)$, sepsis (3), changes in circulatory volume, need for catecholamine treatment, hemorrhagy].

Clinical observation does not deliver sufficient information (4). Invasive (potentially traumatic) and non-invasive blood pressure measurement (5), influenced by vascular resistances, reflects $\mathrm{CO}$ only partially. Electrocardiogram (ECG) and heart rate (HR) variability only give indirect information. NIRS indicates compromised regional circulation possibly related to an underlying general low flow (6) but can deliver no evidence on its cause.

In LBW infants, conventional invasive $\mathrm{CO}$ measurement methods, often considered as "gold standards" like the Swan - Ganz catheter, are too traumatic in these patients, therefore research for non-invasive alternatives is necessary. Transthoracic cardiac ultrasound (TTE) with trans-aortic Doppler (7) is used in daily clinical practice, but is technically highly demanding and can only be applied sporadically. Another possible technique, bioimpedance, referring to thoracic impedance changes by $\mathrm{CO}$-dependent intrathoracic blood flow, has been developed in the 60 s by Kubicek (8). One of its most recent modifications is electrical velocimetry (EV) based on the mathematical algorithms formulated by Bernstein and Lemmens (9) in 2005.

Electrical velocimetry and trans-aortic Doppler have been validated against invasive $\mathrm{CO}$ measurement reference techniques [thermodilution (10,11), Fick (12)]. EV has been evaluated against the Fick and the thermodilution method as gold standards, but data are scarce, the cohorts enrolled in the studies heterogenous, and the results remain controversial concerning the measurement of "true" CO. On the other hand, with special regard to clinical purposes, EV has been found interchangeable with Doppler ultrasound in adults (13) and, recently, evidence was given for the interchangeability of the two methods in newborns with and without underlying congenital heart disease (14-16).

The aim of this method comparison study was to investigate if EV and TTE are even interchangeable in LBW and VLBW infants in order to create a rationale for further clinical validation studies of EV. 


\section{METHODS}

In this prospective, observational study, we performed $228 \mathrm{CO}$ measurements in 28 pre-term newborns (subgroups: 17 LBW, 11 VLBW). Detailed epidemiological data are given in Table 1.

The study was designed as an observational method comparison study for the interchangeability of TTE and EV and not as a clinical validation study. Nevertheless, clinical observations will be communicated for correlation of SV and CO measurements with body weight, and observations for $\mathrm{SV}$ and $\mathrm{CO}$ under inotropic treatment (epinephrine $0.05 \mu \mathrm{g} / \mathrm{kg} / \mathrm{min}$ and milrinone $0.375 \mu \mathrm{g} / \mathrm{kg} / \mathrm{min}$ ) and under different respiration conditions that may illustrate the utility of EV (and TTE) in daily clinical practice.

The local ethical committee's permission and informed parental consent were obtained in accordance with the ethical standards laid down in the 1964 Declaration of Helsinki and its later amendments.

Table 1 | Epidemiological data of the patients enrolled in the study.

\begin{tabular}{ll}
\hline Parameter & Total \\
\hline Number of patients (measurements) & $28(228)$ \\
Number of LBW infants (measurements) & $17(134)$ \\
Number of VLBW infants (measurements) & $11(94)$ \\
Male (patients) & 18 \\
Female (patients) & 10 \\
Mean gestational age (weeks), all patients & $31.7 \pm 3.1$ \\
Mean gestational age (weeks), VLBW & $29.2 \pm 2.8$ \\
Median age at exam (days) & $15(1-48)$ \\
Mean weight at exam (kg), all patients & $1.618 \pm 0.346$ \\
Mean weight at exam (kg), LBW & $1.866 \pm 0.145$ \\
Mean weight at exam (kg), VLBW & $1.236 \pm 0.161$ \\
Patients ventilated (number) & 19 \\
Inotropic support (patients) & 10
\end{tabular}

\section{ELECTRICAL VELOCIMETRY}

Stroke volume (SV) was measured by $\mathrm{EV}$ as $\mathrm{SV}_{\mathrm{EV}}$ using the $\mathrm{ICON}^{\circledR}$ bioimpedance monitor (Osypka Medical, La Jolla, CA, USA). The principles of EV and the method itself have been discussed elsewhere in detail $(9,16) . \mathrm{CO}_{\mathrm{EV}}$ was measured as:

$$
\mathrm{CO}_{\mathrm{EV}}=\mathrm{SV}_{\mathrm{EV}} \times \mathrm{HR}(\mathrm{ml} / \mathrm{min})
$$

and indexed to body weight as $\mathrm{CO}_{\mathrm{EV}}^{*}(\mathrm{ml} / \mathrm{kg} / \mathrm{min}), \mathrm{SV}_{\mathrm{EV}}$ indexed to body weight as $\mathrm{SV}_{\mathrm{EV}}^{*}(\mathrm{ml} / \mathrm{kg})$.

Utmost attention was paid to the best signal quality and ECG and $\mathrm{d} Z / \mathrm{d} t$ curve on the ICON ${ }^{\circledR}$ monitor (Figure 1). Conventional pediatric electrodes were placed according to the recommendations for the use of the ICON ${ }^{\circledR}$ in small children (Figure 1). EV $\left(\mathrm{SV}_{\mathrm{EV}}\right)$ and trans-aortic Doppler measurements of SV ( $\left.\mathrm{SV}_{\mathrm{TTE}}\right)$ were performed simultaneously.

\section{TRANS-AORTIC DOPPLER ULTRASOUND}

$\mathrm{SV}_{\text {TTE }}$ measurements were performed as described in detail by Grollmuss et al. (16). For the measurement of the velocity time integral (VTI), utmost attention was paid to the ultrasound sample being placed directly behind the aortic valve, in line with the blood stream ejected from the left ventricle into the aorta. $\mathrm{CO}_{\mathrm{TTE}}$ and the body weight indexed $\mathrm{CO}_{\mathrm{TTE}}^{*}(\mathrm{ml} / \mathrm{kg} / \mathrm{min})$ were then calculated in analogy to the $\mathrm{EV}$ measurements. $\mathrm{SV}_{\text {TTE }}$ was indexed to body weight as $\mathrm{SV}_{\mathrm{TTE}}^{*}(\mathrm{ml} / \mathrm{kg})$.

In order to minimize artifacts end errors of the EV and TTE measurements that have been described in the literature, in particular referring to the exact measurement of the diameter of the aortic annulus five subsequent measurements were made under optimal measurement and signal conditions and then averaged.

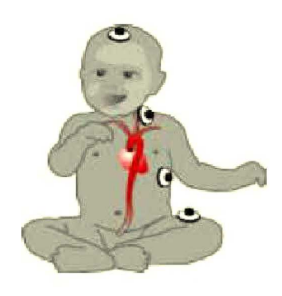

Placement of electrodes across the thorax of the small infant

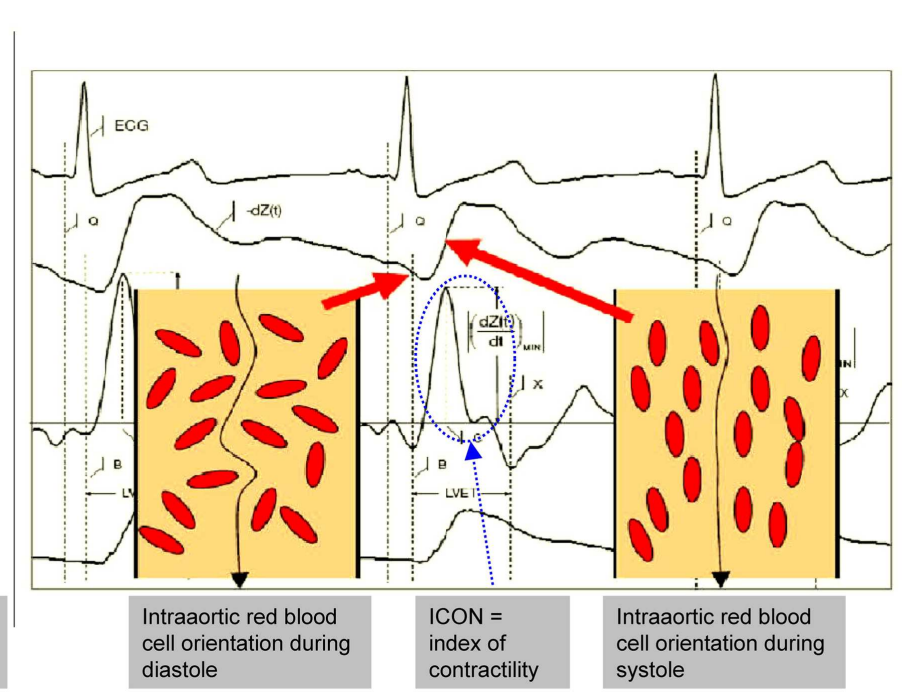

FIGURE 1 | EV - electrode placement in the small infant and EV signals It is important that the electrode placing keeps sufficient distance between the electrodes to avoid interferences and signal disturbances which may be difficult in very small infants. ECG and EV signals must be clearly identified on the monitor as they correlate with the intra-aortic blood flow changes. Further explanations are given in the text. (With kind permission of Osypka Medical, Berlin, Germany and La Jolla, CA, USA, modified for scientific publication by the authors). 


\section{STATISTICAL METHODS}

As neither TTE nor EV represent a gold standard for $\mathrm{CO}$ measurement, they were considered as interchangeable when the limits of agreement for $\mathrm{CO}$ measured by the two methods fulfilled the criteria (30\% of mean) formulated by Critchley and Critchley (17).

SigmaPlot software, version 12.3 (Systat Software, Chicago, IL, USA) was used for method comparison (Bland-Altman Plot), descriptive statistics, group comparison ( $t$-test), and correlation tests (Pearson) (17-19). Differences between the values were considered as significant at $p<0.05$, if not indicated otherwise. Values are given as means $\pm S D$, if not indicated otherwise. The coefficient of variation $(\mathrm{CV})$ was calculated as the expression of the method's precision.

The Doppler $\mathrm{SV}_{\mathrm{TTE}}$ measurements were performed by a certified and experienced specialist in neonatal cardiac ultrasound, who was blind for the simultaneous EV measurements using the ATL hdi 5000 ultrasound machine, now Philips, Andover, MA, USA and the Vivid I and Vivid 7 ultrasound machines, both from GE healthcare, Chalfont St. Giles, Buckinghamshire, UK.

\section{RESULTS}

\section{PATIENTS' DATA}

Mean gestational age of all patients was $31.7 \pm 3.1$ weeks (VLBW $29.2 \pm 2.8$ weeks), $27 / 28$ (=96.4\%) being pre-term born infants with $24 / 28(=85.7 \%)$ being under 35 and $8 / 28$ (=28.6\%) under 30 weeks of gestation (minimal gestational age: 26 weeks). Mean weight of all patients at the time of CO measurement was $1.618 \pm 0.346 \mathrm{~kg}$, mean weight of the VLBW patients $1.236 \pm 0.161 \mathrm{~kg}$, the smallest infant enrolled in the study weighing $0.860 \mathrm{~kg}$. Ten out of 28 patients $(35.7 \%)$ had low dose inotropic support, $19 / 28$ patients $(=67.9 \%)$ were artificially ventilated.

\section{METHOD COMPARISON}

Bland-Altman method comparison for $\mathrm{CO}_{\mathrm{TTE}}^{*}$ and $\mathrm{CO}_{\mathrm{EV}}^{*}$ and precision calculation are given in Table 2 and Figure 2. Bias was consistently positive for all patients and the subgroups with consistently higher $\mathrm{CO}_{\mathrm{EV}}^{*}$ than $\mathrm{CO}_{\mathrm{TTE}}^{*}$ values and clinically acceptable with values $<10 \%$ of the mean of both methods. Limits of agreement for both methods in all patients and the subgroups were below the $30 \%$ limits stipulated by Critchley and Critchley (17) for method interchangeability (Figure 2 ). There was practically no difference of EV and TTE interchangeability for CO measurement between ventilated and non-ventilated infants with bias of $4.0 \%$ of mean in ventilated patients and $2.5 \%$ in non-ventilated patients and limits of agreement of 23.6 and $25.2 \%$ for ventilated and non-ventilated infants, respectively.

\section{PRECISION OF THE METHODS}

Overall CV was $<10 \%$, expressing clinically acceptable precision of TTE [in accordance with Hudson et al. (7)] and EV [in accordance with Grollmuss et al. (16)]. Whereas CV for EV was nearly identical in all groups, CV for TTE was significantly higher in the VLBW than in the LBW group $(p=0.009)$, indicating that CO measurement by trans-aortic Doppler may be technically more difficult in the smallest infants. $\mathrm{CV}$ for $\mathrm{EV}$ in all patients was significantly lower than for TTE $(p=0.046)$ suggesting that EV may be somewhat more precise for $\mathrm{CO}$ measurement in small infants than TTE. There was a significantly higher CV for $\mathrm{CO}_{\mathrm{EV}}^{*}$ in spontaneously breathing (mean $11.2 \pm 8.5 \%$ ) than in ventilated infants (mean $8.2 \pm 9.4 \%, p=0.025$ ), thus less precision for $\mathrm{EV}$ in extubated patients.

\section{DESCRIPTIVE STATISTICS}

Descriptive statistics for $\mathrm{SV}_{\mathrm{TTE}}, \mathrm{SV}_{\mathrm{EV}}, \mathrm{SV}_{\mathrm{TTE}}^{*}, \mathrm{SV}_{\mathrm{EV}}^{*}, \mathrm{CO}_{\mathrm{TTE}}^{*}$, $\mathrm{CO}_{\mathrm{EV}}^{*}$, and $\mathrm{HR}$ are given in Table 3 .

\section{Stroke volume}

As could be expected, $\mathrm{SV}_{\mathrm{TTE}}$ and $\mathrm{SV}_{\mathrm{EV}}$ were significantly lower in VLBW patients compared to those in the LBW group due to their smaller anatomic dimensions $(p<0.001)$ whereas there was no statistically significant difference between VLBW and LBW infants for $\mathrm{SV}_{\mathrm{TTE}}^{*}$ and $\mathrm{SV}_{\mathrm{EV}}^{*}$. Correlation between $\mathrm{SV}_{\mathrm{TTE}}$ and body weight was $r=0.77$ and between $\mathrm{SV}_{\mathrm{EV}}$ and body weight $r=0.81$.

\section{Cardiac output}

$\mathrm{CO}_{\mathrm{TTE}}^{*}$ and $\mathrm{CO}_{\mathrm{EV}}^{*}$ were higher in the VLBW than in the LBW group ( $p=0.009$ for $\mathrm{CO}_{\mathrm{TTE}}^{*}$ and 0.002 for $\mathrm{CO}_{\mathrm{EV}}^{*}$ ) due to a significantly higher HR in the VLBW group compared to the LBW patients $(p<0.001)$.

\section{Inotropic treatment}

$\mathrm{SV}$ and $\mathrm{SV}^{\star}$ were higher in patients with inotropic treatment $\left(\mathrm{SV}_{\mathrm{EV}} 2.88 \pm 0.83 \mathrm{ml}, \mathrm{SV}_{\mathrm{EV}}^{*} 1.73 \pm 0.24 \mathrm{ml}\right)$ than in those

Table 2 | Bland-Altman test for method agreement and coefficient of variations (CV) for precision calculation in all patients, LBW and VLBW infants.

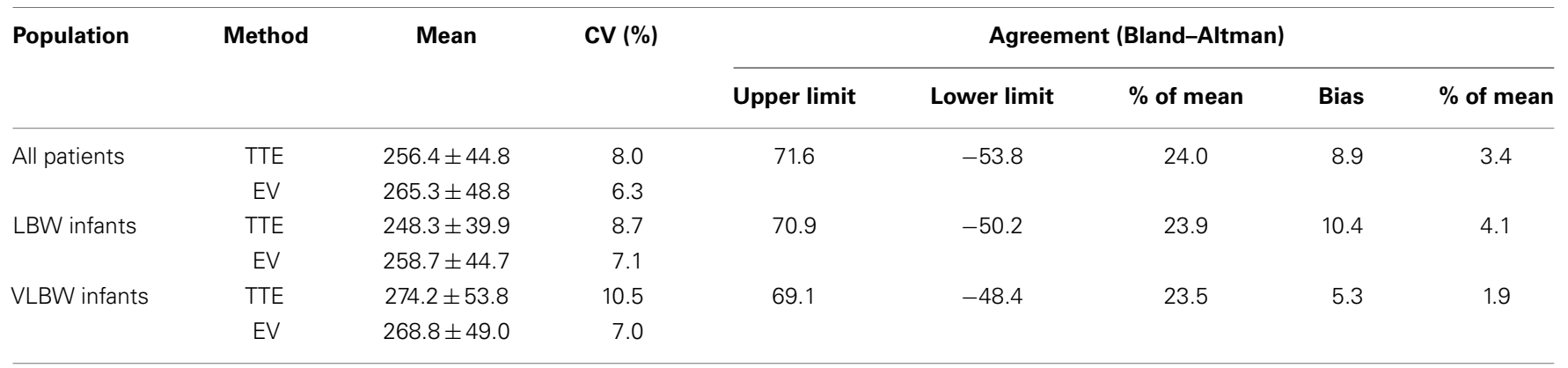

Means, bias, and limits are expressed as absolute values ( $\mathrm{m} / \mathrm{kg} / \mathrm{min})$, bias and limits also as \% of means. 

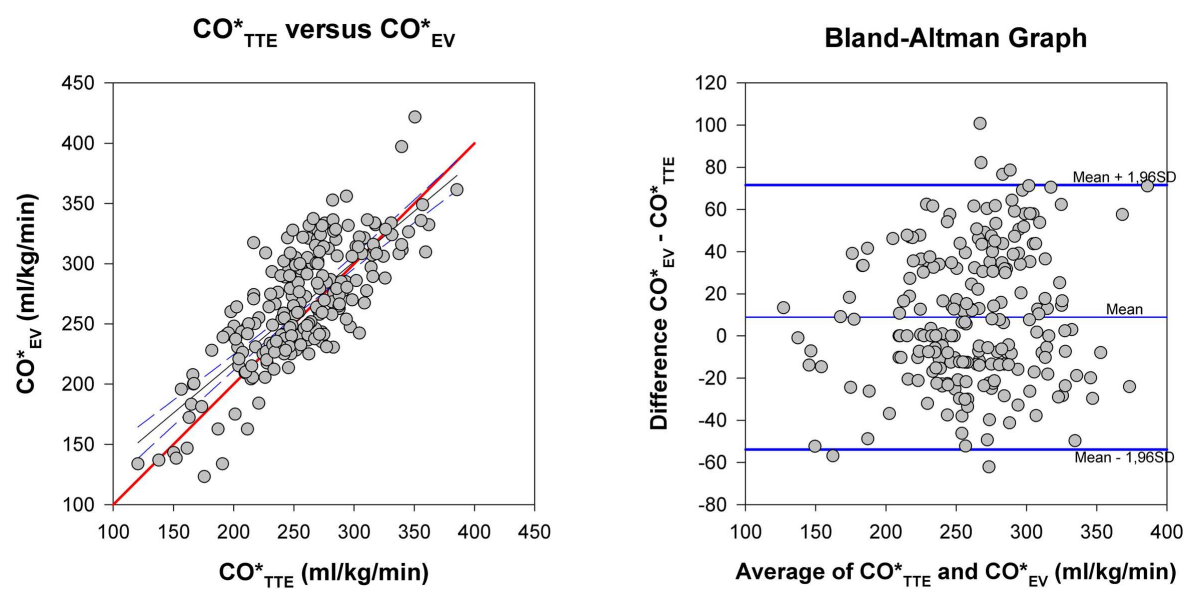

FIGURE 2 | Method comparison. Left: $\mathrm{CO}^{*}{ }_{T T E}$ versus $\mathrm{CO}^{*}{ }_{\mathrm{EV}}$. The thick (red) line is the line of identity. Right: Bland-Altman plot for differences of $\mathrm{CO}^{*}{ }_{\mathrm{EV}}-\mathrm{CO}^{*}{ }_{\mathrm{TTE}}$ against the average of the two methods. Thick (blue) lines: limits of agreement, thin (blue) line: mean of the methods. Its distance to the zero line is the bias of the two methods.

Table 3 | Circulatory parameters: Measured SV, body weight indexed SV*, HR, and body weight indexed CO* for all patients, LBW and VLBW.

\begin{tabular}{|c|c|c|c|c|c|c|c|}
\hline \multirow[t]{2}{*}{ Parameter population } & \multicolumn{2}{|c|}{ SV (ml) } & \multicolumn{2}{|c|}{$\mathrm{SV}^{*}(\mathrm{ml} / \mathbf{k g})$} & \multirow{2}{*}{$\begin{array}{c}\text { HR (beats/min) } \\
\text { ECG (EV) }\end{array}$} & \multicolumn{2}{|c|}{$\mathrm{CO}^{*}(\mathrm{ml} / \mathrm{kg} / \mathrm{min})$} \\
\hline & TTE & EV & TTE & EV & & TTE & EV \\
\hline LBW & $3.31 \pm 0.53$ & $3.46 \pm 0.56$ & $1.62 \pm 0.25$ & $1.69 \pm 0.25$ & $158.2 \pm 10.8$ & $247.7 \pm 39.8$ & $259.1 \pm 44.1$ \\
\hline VLBW & $2.49 \pm 0.58$ & $2.45 \pm 0.58$ & $1.65 \pm 0.29$ & $1.68 \pm 0.31$ & $163.5 \pm 12.3$ & $268.8 \pm 49.0$ & $274.2 \pm 53.8$ \\
\hline
\end{tabular}

Measurements performed by TTE and EV.

without catecholamine treatment $\left(\mathrm{SV}_{\mathrm{EV}} 2.51 \pm 0.41 \mathrm{ml}, p=0.002\right.$, $\left.\mathrm{SV}_{\mathrm{EV}}^{*} 1.65 \pm 0.29 \mathrm{ml}, p=0.031\right)$. HR was significantly in patients without $(163.5 \pm 9.1$ beats $/ \mathrm{min})$ than with inotropic treatment $(159.5 \pm 12.2$ beats $/ \mathrm{min}, p=0.044)$. Consequently, $\mathrm{CO}^{*}$ was significantly higher in these patients, too $\left(\mathrm{CO}_{\mathrm{EV}}^{*} 275 \pm 40.9\right.$ vs. $258.6 \pm 52.3 \mathrm{ml} / \mathrm{kg} / \mathrm{min}, p=0.009$ ).

\section{Ventilation effects}

For all patients, $\mathrm{CO}_{\mathrm{EV}}^{*}(270.9 \pm 47.6 \mathrm{ml} / \mathrm{kg} / \mathrm{min})$ in ventilated infants was higher than in non-ventilated patients $\left(\mathrm{CO}_{\mathrm{EV}}^{*}\right.$ $252.5 \pm 49.3 \mathrm{ml} / \mathrm{kg} / \mathrm{min}, p=0.024)$ based on a higher $\mathrm{SV}_{\mathrm{EV}}$ $\left(2.77 \pm 0.70 \mathrm{ml}, \mathrm{SV}_{\mathrm{EV}}^{*} 1.71 \pm 0.25 \mathrm{ml}\right)$ in the ventilated group compared to the non-ventilated patients $\left(\mathrm{SV}_{\mathrm{EV}} 2.55 \pm 0.72 \mathrm{ml}, \mathrm{SV}_{\mathrm{EV}}^{*}\right.$ $1.63 \pm 0.32, p=0.031$.

\section{DISCUSSION}

This study was a pure observational method comparison of EV and TTE in LBW and VLBW infants with supplementary clinical observations indicating a possible use of EV in daily neonatological and cardiological practice. It was not designed to evaluate a "true" CO comparing EV to a convened gold standard like Fick's method or thermodilution, which is not possible in very small infants, but to explore the utility of EV as an easily feasible alternative to the technically demanding trans-aortic Doppler for the measurement of $\mathrm{CO}$ in these patients.
Method comparison of the two non-invasive CO measurement methods, TTE and EV, shows that they are interchangeable, fulfilling the criteria of Critchley and Critchley (17), with narrow limits of agreement, low and constant bias, and, finally, good precision of either method with EV being somewhat more precise than TTE.

Method interchangeability was not altered by the respiratory mode (ventilation or spontaneous respiration) whereas $\mathrm{CO}_{\mathrm{EV}}^{*}$ measurements were significantly less precise in extubated than in ventilated infants suggesting a particularly careful interpretation of EV in these patients as movements of the awake-patients might interfere with the EV signal.

Stroke volume correlated well with the patients' body weight and was therefore higher in LBW than in VLBW patients, thus reflecting correctly the patients' differences of weight and age. As the body weight related $\mathrm{SV}^{*}$ was not different in the two groups, the paradoxically higher $\mathrm{CO}^{*}$ in the VLBW group was obviously due to a higher HR in these patients.

The higher SV and CO in ventilated patients may be due to positive effects of positive intrathoracic pressure on left ventricular (LV) afterload reduction as has been previously reported $(1,2)$.

Extending the previous studies in normal weight newborns $(15,16)$, the present study shows that EV and TTE are also interchangeable even in LBW and VLBW infants, fulfilling the criteria of Critchley and Critchley (17) for method comparison of two 
non-reference methods, with clinically acceptable precision of $\mathrm{CO}$ measurement by EV (16).

As a conclusion, EV may represent a valuable tool for CO monitoring in LBW and VLBW infants, particularly helpful in detecting imminent risks of low $\mathrm{CO}$ (16) associated to the pathology of very small and pre-term newborns like circulatory degradation in the case of sepsis or bleeding, and it may help to conduct volume substitution treatment. These aspects of a possible role of EV in the critical care management of very small NICU or PCICU patients should be evaluated by further, clinical studies.

Compared to TTE, the advantage of EV may be a continuous and relatively easy manageable $\mathrm{CO}$ monitoring completing the "traditional" circulatory monitoring in neonatal, pediatric, and pediatric cardiological intensive care units. Its clinical utility still needs to be confirmed, but evidence is growing $(15,16)$. In fact, the clinical observations of the present study with regard to variations of $\mathrm{SV}_{\mathrm{EV}}, \mathrm{SV}_{\mathrm{EV}}^{*}$, and $\mathrm{CO}_{\mathrm{EV}}^{*}$ related to weight, ventilation, and inotropic treatment support a potential role of $\mathrm{EV}$ in the clinical practice of $\mathrm{CO}$ monitoring even in very small infants.

\section{ACKNOWLEDGMENTS}

The authors wish to thank their colleagues of the Institut de Puériculture et de Périnatalogie (IPP), Paris, the SMUR 92 (Centre Hospitalier Universitaire Antoine Béclère), Clamart, and the Centre Chirurgical Marie Lannelongue, Le Plessis Robinson, France, for their help. Many thanks to Constance, Julien, Douceline, and Roméo.

\section{REFERENCES}

1. Pinsky MR. Recent advances in the clinical application of heart-lung interactions. Curr Opin Crit Care (2002) 8:26-31. doi:10.1097/00075198-20020200000005

2. Shekerdemian L, Bohn D. Cardiovascular effects of mechanical ventilation. Arch Dis Child (1999) 80:475-80. doi:10.1136/adc.80.5.475

3. Polin RA, The Committee on Fetus and Newborn. Management of neonates with suspected or proven early-onset bacterial sepsis. Pediatrics (2012) 129:1006. doi:10.1542/peds.2012-0541

4. Tibby SM, Hatherill M, Marsh JJ, Murdoch I. Clinicians' abilities to estimate cardiac index in ventilated children and infants. Arch Dis Child (1997) 77:516-8. doi:10.1136/adc.77.6.516

5. Nwankwo MU, Lorenz JM, Gardiner JC. A standard protocol for blood pressure measurement in the newborn. Pediatrics (1997) 99:e10. doi:10.1542/ peds.99.6.e10

6. Mittnacht AJ. Near infrared spectroscopy in children at high risk of low perfusion. Curr Opin Anaesthesiol (2010) 23(3):342-7. doi:10.1097/ACO. 0b013e3283393936

7. Hudson I, Houston A, Aitchison T, Holland B, Turner T. Reproducibility of measurements of cardiac output in newborn infants by Doppler ultrasound. Arch Dis Child (1990) 65:15-9. doi:10.1136/adc.65.1_Spec_No.15

8. Kubicek WG, Karnegis JN, Patterson RP, Witsoe DA, Mattson RH. Development and evaluation of an impedance cardiac output system. Aerosp Med (1966) 37(12):1208-12.
9. Bernstein DP, Lemmens HJ. Stroke volume equation for impedance cardiography. Med Biol Eng Comput (2005) 43(4):443-50. doi:10.1007/BF02344724

10. Tomaske M, Knirsch W, Kretschmar O, Woitzek K, Balmer C, Schmitz A, et al. Working group on non-invasive haemodynamic monitoring in paediatrics. Cardiac output measurement in children: comparison of Aesculon cardiac output monitor and thermodilution. Br J Anaesth (2008) 100(4):517-30. doi:10.1093/bja/aen024

11. Zoremba N, Bickenbach J, Krauss B, Rossaint R, Kuhlen R, Schälte G. Comparison of electrical velocimetry and thermodilution techniques for the measurement of cardiac output. Acta Anaesthesiol Scand (2007) 51:1314-9. doi:10.1111/ j.1399-6576.2007.01445.x

12. Norozi K, Beck C, Osthaus WA, Wille I, Wessel A, Bertram H. Electrical velocimetry for measuring cardiac output in children with congenital heart disease. Br J Anaesth (2007) 100(1):88-94. doi:10.1093/bja/aem320

13. Schmidt C, Theilmeier G, van Aken H, Korsmeier P, Wirtz SP, Berendes E, et al. Comparison of electrical velocimetry and transoesophageal Doppler echocardiography for measuring stroke volume and cardiac output. Br J Anaesth (2005) 95:603-10. doi:10.1093/bja/aei224

14. Schubert S, Schmitz T, Weiss M, Nagdyman H, Huebler M, Alexi-Meskishvili V, et al. Continuous, non-invasive techniques to determine cardiac output in children after cardiac surgery: evaluation of transesophageal Doppler and electric velocimetry. J Clin Monit Comput (2008) 22:299-307. doi:10.1007/s10877-0089133-0

15. Noori S, Drabu B, Soleymani S, Seri I. Continuous non-invasive cardiac output measurements in the neonate by electrical velocimetry: a comparison with echocardiography. Arch Dis Child Fetal Neonatal Ed (2012) 97:F340-3. doi:10.1136/fetalneonatal-2011-301090

16. Grollmuss O, Demontoux S, Capderou A, Serraf A, Belli E. Electrical velocimetry as a tool for measuring cardiac output in small infants after heart surgery. Intensive Care Med (2012) 38(6):1032-9. doi:10.1007/s00134-012-2530-3

17. Critchley LA, Critchley JA. A meta-analysis of studies using bias and precision statistics to compare cardiac output measurement techniques. J Clin Monit Comput (1999) 15(2):85-91. doi:10.1023/A:1009982611386

18. Bland M, Altman DG. Statistical methods for assessing agreement between two methods of clinical measurement. Lancet (1986) 1(8476):307-10. doi:10.1016/ S0140-6736(86)90837-8

19. Preiss D, Fisher J. A measure of confidence in Bland-Altman analysis for the interchangeability of two methods of measurement. JClin Monit Comput (2008) 22:257-9. doi:10.1007/s10877-008-9127-y

Conflict of Interest Statement: The Review Editor Yves Durandy declares that, despite being affiliated to the same institution as author Oswin Grollmuss, the review process was handled objectively and no conflict of interest exists. The other co-author reports no conflicts of interest.

Received: 10 December 2013; accepted: 05 March 2014; published online: 25 March 2014.

Citation: Grollmuss $O$ and Gonzalez P (2014) Non-invasive cardiac output measurement in low and very low birth weight infants: a method comparison. Front. Pediatr. 2:16. doi: 10.3389/fped.2014.00016

This article was submitted to Pediatric Cardiology, a section of the journal Frontiers in Pediatrics.

Copyright (c) 2014 Grollmuss and Gonzalez. This is an open-access article distributed under the terms of the Creative Commons Attribution License (CC BY). The use, distribution or reproduction in other forums is permitted, provided the original author(s) or licensor are credited and that the original publication in this journal is cited, in accordance with accepted academic practice. No use, distribution or reproduction is permitted which does not comply with these terms. 